\title{
Psicologia da educação matemática: um ponto de vista
}

\section{Psychology of mathematics education: a point of view}

\author{
Márcia Regina Ferreira de Brito ${ }^{1}$
}

\begin{abstract}
RESUMO
A apresentação trata da evolução da chamada psicologia da educação matemática no Brasil, traçando os temas e as linhas teóricas desenvolvidas pelo Grupo de Pesquisa em Psicologia e Educação Matemática (PSIEM) da FE/UNICAMP, surgido no final da década de setenta. Tendo como pano de fundo o momento no qual eram desenvolvidos esses trabalhos, terão destaque para traçar essa evolução os métodos de pesquisa empregados, os problemas escolhidos e as teorias subjacentes, apontando as dificuldades encontradas. Assim, iniciando com a formação de professores de matemática e com os temas da psicologia educacional que são essenciais para formar "bons pensadores", serão abordados aspectos de desenvolvimento, aprendizagem, ensino, desempenho e avaliação, com ênfase em: aprendizagem de conceitos, solução de problemas, atitudes em relação à matemática e a maneira como esses temas têm sido tratados. Serão ainda apresentados alguns elementos que, de certa forma, têm dificultado a disseminação dos resultados desses estudos.

Palavras-chave: psicologia da educação matemática brasileira; psicologia e ensino-aprendizagem da matemática; produção científica grupo PSIEM/ UNICAMP.
\end{abstract}

\footnotetext{
ABSTRACT

The paper deals with some aspects of the history of the so called psychology of the mathematics education in Brazil. It is focused on subjects and theoretical approaches developed by the research group of psychology and

1 Doutora em Psicologia. Professora livre-docente da Faculdade de Educação da Universidade Estadual de Campinas, (FE/UNICAMP), São Paulo, Brasil.
} 
mathematics education (PSIEM) FE/UNICAMP, whose activities began in the late seventies. According to the context where those studies were carried out, and in order to outline that history, the research methods, the chosen problems and the supporting theories will be emphasized, and also the difficulties faced with. First of all, the question of the mathematics teacher's education and those constructs of the educational psychology is discussed, which is relevant to the education of "good thinkers", as: development, learning, teaching, performance and assessment. Propositions about concept learning, problem solving, attitudes regarding mathematics and how these issues have been studied are underlined. Moreover, some elements which bring about some difficulties to the dissemination of those research results are presented.

Keywords: psychology of mathematics education in Brazil; psychology and mathematics teaching and learning; scientific production of the PSIEM/ UNICAMP group.

Gostaria de agradecer o convite que me foi feito pela comissão organizadora do evento para proferir a palestra inaugural desse simpósio que reúne muitas das pessoas que fizeram a história da Educação Matemática no Brasil. Os desencontros de caminhos e ideias e os múltiplos compromissos que a vida nos impõe não permitem, muitas vezes, que a união de ideias leve rapidamente ao avanço dessa área tão necessária ao desenvolvimento do País. Na pessoa das Professoras Maria Lucia Faria Moro e Maria Tereza Carneiro Soares gostaria de saudar a todos os presentes.

Gostaria, de maneira particular, de saudar o Professor Doutor Gérard Vergnaud, figura central desse evento, que tem papel de destaque no avanço e compreensão dos temas da Psicologia que são de fundamental importância para a compreensão das aquisições de conceitos matemáticos, tanto no ambiente escolar como fora dele. Pesquisador reconhecido no cenário internacional, contribuiu de maneira inquestionável na formação de pesquisadores brasileiros, seja pela abertura à participação desses em seu grupo, como pela leitura e estudos de seus escritos.

Quando a Professora Maria Lucia me convidou para essa palestra, a tarefa me pareceu bastante simples, talvez pela distância no tempo. Porém, à medida que o tempo se esgotava e fiel a um princípio muito importante da aprendizagem, que é o tempo que um indivíduo é capaz de manter seu foco de atenção em um único elemento, me deparei com a difícil tarefa de apresentar em 50 minutos meu ponto de vista sobre a evolução do nosso grupo de Psicologia da Educação Matemática desde o surgimento, no final da década de setenta, até o momento atual. Restringindo muito os tópicos que poderiam ser tratados, em 
minha fala, com certeza, essa exposição deixará de lado aspectos importantes da área e, desde já, peço desculpas por isso.

\section{Desenvolvimento de trabalhos na área de Educação Matemática}

Em 1976, quando conclui minha dissertação de mestrado sobre a solução de problemas, tendo como sujeitos estudantes de graduação de Matemática, Química e Física, os estudos a respeito do pensamento matemático, da capacidade de solucionar problemas, das maneiras de aprender e processar a informação na área de Exatas e Tecnológicas passaram a ser o foco de minha atenção. Nessa mesma época, 1976, participei do projeto LOGO na UNICAMP. Minha atividade no projeto consistia em acompanhar as crianças durante a execução de tarefas que envolviam a geometria, anotando as questões levantadas por elas, as respostas dadas e perguntando-lhes por que haviam escolhido aquela forma de atuação. Ainda em 1976, por sugestão do Professor Ubiratan D'Ambrósio, comecei a acompanhar os trabalhos internacionais sobre solução de problemas e matemática. Em 1978, juntamente com alguns professores das licenciaturas da Faculdade de Educação e alguns professores do Instituto de Matética, Estatística e Computação Científica da Universidade Estadual de Campinas (IMECC/UNICAMP), elaboramos o Projeto Integrado de Matemática que, infelizmente, não produziu bons resultados. Nesse período era professora da disciplina Psicologia da Aprendizagem I para alunos de Ciências Exatas e as teorias apresentadas eram as teorias de condicionamento, particularmente a teoria operante de Skinner e a teoria da aprendizagem cumulativa de Robert Gagné.

Durante o período de mestrado e doutorado, sempre sob orientação de Joel Martins, tive oportunidade de assistir aos cursos de David Ausubel sobre aprendizagem significativa e, também, os de Amedeo Giorgi a respeito da fenomenologia. As ideias desses autores moldaram de certa forma os trabalhos que desenvolvo. Durante o doutorado me dediquei aos estudos da fenomenologia com o professor Joel que então iniciava seus trabalhos na área. Aluna de um curso de psicologia no início da década de setenta (cujo caráter era eminentemente behaviorista), fui contratada pela UNICAMP em 1974 para dar aulas sobre as teorias de condicionamento. No mestrado estabeleci uma comparação entre a aprendizagem significativa e aquela por tentativa e erro, usando para tanto a solução de problemas. Esse trabalho me levou a estabelecer as relações entre o comportamento e a cognição, superando a dicotomia que nos é ensinada e que contrapõe aquelas teorias, dicotomia esta que não permite aos estudantes visualizar as profundas relações que existem entre aquelas dimensões. A salientar que, na verdade, para um 
bom entendimento sobre o que é o processamento da informação, o pesquisador precisa conhecer profundamente a abordagem comportamental.

Após concluir o doutorado iniciei minhas atividades na pós-graduação. Exceto por dois trabalhos de doutorado, três de pós-doutorado e quatro de mestrado, todos os estudos realizados no grupo de Psicologia da Educação Matemática da FE/ UNICAMP são trabalhos que, do ponto de vista da psicologia educacional, são da área da psicologia aplicada à aprendizagem - ensino de matemática. Foram vinte teses de doutorado (treze estudantes graduados em Matemática, dois em Estatística, um em Pedagogia e três em Psicologia); vinte e duas dissertações de mestrado (doze estudantes graduados em Matemática, um em Estatística, seis em Pedagogia e três em Psicologia); seis trabalhos de iniciação científica; uma monografia de final de curso e um pós-doutorado. Essas cinquenta pesquisas acompanham a evolução do grupo e, juntamente com os dezessete trabalhos supervisionados pela professora Lucila Fini, perfazem um total de sessenta e sete pesquisas concluídas nos vinte e cinco anos de existência do grupo. Além disso, vale ressaltar que o grupo de Psicologia da Educação Matemática da UNICAMP foi registrado junto ao CNPq desde o início do Diretório dos Grupos de Pesquisa em 1986.

Em 1996, o grupo de Psicologia Educacional da ANPEPP (Associação Nacional de Pesquisa e Pós-Graduação em Psicologia) subdividiu-se em vários outros, dada a diversidade de assuntos abordados. Foi então proposto o grupo de Psicologia da Educação Matemática que congregava pesquisadores das Faculdades de Educação e de cursos de Psicologia da Universidade Federal do Paraná (UFPR), Universidade Federal do Rio de Janeiro (UFRJ), Universidade Federal de Pernambuco (UFPE), Universidade Estadual Paulista (UNESP), Universidade Estadual de Campinas (UNICAMP), Universidade Católica Dom Bosco (UCDB) e Pontifícia Universidade Católica de São Paulo (PUCSP). Esse grupo produziu trabalhos e encontros importantes, mas a proposta original da associação, que era a discussão dos pesquisadores de programas de pós-graduação, não existe mais $\mathrm{e}$, a meu ver, o grupo passou a ser um congresso a mais. $\mathrm{O}$ grupo de pesquisa em Psicologia da Educação Matemática da ANPEPP foi formado a partir do interesse comum em estudar, do ponto de vista das teorias cognitivas: o desenvolvimento do pensamento matemático, a aquisição e a retenção do conhecimento matemático, as relações entre a Matemática e as demais disciplinas e aspectos relacionados ao ensino dessa disciplina, particularmente em relação à afetividade e à motivação.

Com relação aos aspectos teóricos do grupo PSIEM (Psicologia e Educação Matemática) da UNICAMP, inicialmente os estudos eram centrados mais em formação de conceitos e solução de problemas, usando o modelo de aprendizagem cumulativa de Robert Gagné e comparando os níveis de desenvolvimento cognitivo com base nos estudos de Klausmeier e Nelson. Especial ênfase sempre foi dada à passagem do conceito como construto mental (próprio de cada sujeito) para o cons- 
truto como entidade pública (conhecimento que é ensinado nas escolas e aceito pelos pesquisadores da área), pois essa passagem é um ponto crítico da aprendizagem.

A seguir, no final da década de oitenta, a partir da leitura dos trabalhos de Albert Bandura, comecei a me interessar pela teoria social cognitiva e iniciei um projeto a respeito das atitudes em relação à Matemática. Elaborei uma revisão detalhada a respeito do tema chegando até os primeiros estudos realizados na década de quarenta a respeito da ansiedade matemática. Interessante notar que só agora, quase vinte anos depois do início desses trabalhos pelo grupo, o tema começa a ser mencionado pelos gestores. Por exemplo, o Secretário de Educação de São Paulo afirmou em reportagem jornalística recente que as crianças de sexta e sétima série foram mal no exame de Matemática chamado Sistema de Avaliação de Rendimento Escolar do Estado de São Paulo (SARESP) ou no Sistema Nacional de Avaliação da Educação Básica (SAEB) devido à passagem da Aritmética para a Álgebra. Esse foi o recorte feito da pesquisa sobre atitudes que apresentei em evento do PME (Grupo Internacional de Psicologia da Educação Matemática) no Recife. Vários trabalhos do grupo PSIEM (UTSUMI, 2000; QUINTILIANO, 2005 entre outros) mostraram o mesmo resultado. Um outro exemplo é o da opção profissional, isto é, a escolha por cursos que envolvem matemática. Na reunião do CONFEA (Confederação dos Engenheiros e Arquitetos do Brasil), realizada recentemente em Brasília, o presidente dessa entidade apontou a importância da matemática para a formação do engenheiro.

\section{Alguns aspectos conceituais}

Passarei agora a tratar de aspectos mais conceituais do que se convencionou chamar de psicologia da educação matemática. Uma primeira observação, que me permito fazer, é que muitas vezes me causa inquietação o uso da denominação "psicologia da educação matemática", pois isso remete à segmentação de uma área dando a impressão (falsa) de que existe uma psicologia educacional diferente e exclusiva da matemática, quando na verdade o mais adequado seria nos referirmos à psicologia educacional e matemática escolar. Neste caso, estaríamos mais vinculados àquilo que Robert Gagné tão propriamente chamou de domínio de área. A psicologia da educação matemática trata, basicamente, da aplicação da psicologia educacional à matemática, prioritariamente à matemática escolar. Acompanhando os trabalhos do PME durante muito tempo, observei que gradativamente foram sendo deixados de lado os estudos a respeito dos aspectos psicológicos, a favor da ênfase apenas no ensino de matemática. Em minha opinião, o PME hoje é muito mais um encontro 
de Didática da Matemática do que uma ocasião de discussão aprofundada a respeito da psicologia educacional aplicada ao ensino da matemática.

Outro aspecto que merece ser destacado é a maneira de se abordar um problema de pesquisa e como os resultados são divulgados. Ao invés de buscar um problema, ler toda a literatura a respeito e daí extrair o método mais adequado para colher informações a respeito do tema e a melhor maneira de fundamentar o estudo, muitos pesquisadores escolhem um caminho diferente que pode levar a resultados equivocados. Em primeiro lugar é escolhido um tema (que nem sempre constitui um problema de pesquisa), adotado um procedimento de pesquisa e posteriormente tenta-se encaixar o resultado na teoria previamente escolhida. Essa maneira de fazer pesquisa leva a resultados que não correspondem à realidade e, de certa maneira, acabam influindo negativamente no ambiente escolar.

É inegável a importância da relação entre a aprendizagem informal proporcionada pelos eventos e relações do cotidiano e a aprendizagem formal acadêmica. A importância das aprendizagens anteriores (cognitivas, afetivas e comportamentais) trazidas para as instituições escolares e a importância das aprendizagens informais é reconhecida na literatura, em geral. Relacionada à natureza da aprendizagem, é consagrada a proposição de que se constrói o conhecimento complexo a partir das experiências, pois os esquemas mentais são construídos em uma hierarquia cada vez mais complexa, sendo a aprendizagem entendida como ativa, volitiva e mediada interna e socialmente. A aprendizagem é um processo de descoberta, de construção pessoal e de significados compartilhados, que são obtidos a partir da informação e da experiência, filtrados pelas percepções, sentimentos e pensamentos, bem como da negociação com os outros.

O conhecimento escolar construído pelo sujeito usa formas significativas próprias a partir do estabelecimento de elos significativos entre o novo material e os elementos já presentes na estrutura cognitiva. Nessa concepção, tem destaque o papel do professor e o contexto no qual a aprendizagem ocorre, sendo esta aprendizagem fortemente influenciada pelos fatores ambientais (cultura, tecnologia e práticas educacionais). Cabe ao professor atuar como mediador entre o ambiente e os sujeitos da aprendizagem buscando conhecer os aspectos inerentes ao contexto e considerá-los ao elaborar o planejamento da sua disciplina.

Além disso, os professores necessitam conhecer e compreender os diferentes tipos de pensamento e buscar formas de aplicar esse entendimento diretamente ao ensino. Necessitam também adquirir familiaridade com os três tipos de pensamento da teoria triádica (pensamento analítico, pensamento criativo e pensamento prático), pois estes são poderosas ferramentas para os estudantes, tanto na sala de aula como fora dela.

Nessa concepção, o objetivo principal da escola é o de formar bons pensadores. Assim, os professores, além de dominar o conteúdo específico 
que ensinam e os recursos metodológicos também devem conhecer e ensinar processos de pensamento, apoiados na crença de que levar os estudantes a desenvolver plenamente o potencial de pensamento é um dos objetivos mais importantes da educação.

Em adição a estes aspectos da aprendizagem cumpre destacar o papel da motivação intrínseca para aprender, que reflete aspectos inerentes ao aprendiz e à tarefa de aprendizagem. A curiosidade natural leva a maioria dos sujeitos a gostar de aprender situações novas e desafiadoras sendo que estas despertam a criatividade, a curiosidade e a intuição. Mas isso se mantém ao longo dos anos, acompanhando os estudantes até a Universidade? Existe considerável evidência empírica mostrando que as tarefas que são identificadas com o cotidiano e com a atividade profissional futura são percebidas como interessantes, relevantes e significativas, são motivadoras e levam ao desenvolvimento da flexibilidade de pensamento. Deve ser considerado, ainda, se o grau de dificuldade e a complexidade da tarefa são apropriados às habilidades do aprendiz e ao nível de desenvolvimento conceitual exigido.

Um outro aspecto a ser considerado refere-se ao papel da motivação e às relações desta com o esforço que o estudante se dispõe a empregar em uma determinada tarefa. Muito provavelmente, o estabelecimento de relações entre o cotidiano dos sujeitos e o conteúdo formal da disciplina facilita a aquisição do conhecimento complexo.

Porém, será impossível aqui, no breve espaço de tempo disponível, trabalhar com fatores tão complexos como alguns dos já mencionados. Em adição, e para os propósitos dessa apresentação, é necessário que sejam entendidos alguns conceitos, pois é em torno deles que essa apresentação será desenvolvida.

\section{Alguns conceitos essenciais}

Desde seus primórdios, a psicologia, independente da abordagem, discorre sobre temas como maturação, desenvolvimento, aprendizagem, ensino e solução de problemas, existindo numerosos estudos que tratam desta diferenciação. Embora não haja acordo total sobre as definições e processos envolvidos, podese verificar uma série de elementos comuns sobre os quais parece não haver nenhuma discordância.

Gostaria de abrir um rápido parêntese para destacar a importância da distinção entre teorias implícitas e teorias explícitas. Em uma diferenciação extremamente simplificada, podemos dizer que a primeira refere-se ao conheci- 
mento que qualquer indivíduo apresenta sobre um determinado tema, enquanto a segunda é baseada em evidências que dependem de comprovação e aceitação. Se perguntarmos a várias pessoas o que entendem por aprendizagem, elas terão alguma resposta elaborada a partir de suas próprias experiências. Mas isso não significa que seja a resposta estabelecida pela ciência psicológica nem que expresse o significado estabelecido e aceito pelos pesquisadores da área. No caso da psicologia da educação matemática muitas vezes as definições estão mais próximas de teorias implícitas do que de teorias explícitas, e é necessário que os pesquisadores tenham cautela no trato desses conceitos.

Maturação se refere a um incremento na capacidade dos indivíduos, sendo estas ocorrências verificadas na ausência de uma experiência específica de aprendizagem. São ocorrências que podem ser atribuídas às experiências acidentais e/ou às influências genéticas que afetam o substrato neuroanatômico e neurofisiológico do comportamento, da percepção, da memória e assim sucessivamente (AUSUBEL; NOVACK; HANESIAN, 1978) (ver também, BRITO, 2001).

Termos como aprendizagem, desenvolvimento e aquisição de competências, que são essenciais para a compreensão das situações escolares, apresentam divergências entre diferentes autores, porém com relação à aprendizagem os autores concordam que aprendizagem:

a) refere-se ao aparecimento de algo novo (destreza, função ou nível); logo, aprendizagem implica mudança;

b) implica procedimentos contínuos e descontínuos;

c) que supõem uma direcionalidade.

A aprendizagem é um processo que envolve as esferas cognitiva, afetiva e motora e pode ser inferida a partir de mudanças relativamente permanentes no comportamento, resultantes da prática; porém, estas mudanças não podem ser confundidas com as mudanças causadas pela maturação biológica ou pela atuação de fatores externos como drogas e fadiga.

A maneira como a aprendizagem acontece (o "momento" em que o indivíduo aprende alguma coisa, se é que podemos falar isso) é diferente da maneira como ele vai incorporar esta nova aprendizagem, possibilitando uma maior ou menor retenção do material aprendido e uma maior ou menor transferência dessa aprendizagem para novas situações e seu posterior uso. Assim, 'tipo de aprendizagem' refere-se aos mecanismos disponibilizados e exigidos por diferentes situações e "formas de aprendizagem" (mecânica e significativa); também refere-se à maneira como os novos elementos aprendidos são retidos na estrutura cognitiva.

Isso significa que, dependendo do que vai ser aprendido, diferentes mecanismos de aprendizagem serão acionados e, dependendo da situação na qual a aprendizagem ocorre, o objeto a ser aprendido será processado diferentemente, 
além de incorporado e retido na estrutura cognitiva de formas distintas. Aqui, "situação de aprendizagem" deve ser entendida como todos os componentes externos e internos ao aprendiz, particularmente as experiências passadas.

Além disso, deve ser considerado que existem diferentes tipos de aprendizagem e que nem todas as coisas são aprendidas da mesma maneira. Decorar um poema é diferente de aprender um algoritmo e ser capaz de aplicar esse algoritmo a problemas semelhantes, transferindo assim a aprendizagem de uma situação para outra.

Podemos considerar que existem os seguintes tipos de aprendizagem que vão ser disponibilizados de acordo com a tarefa e o material apresentado: aprendizagem de sinais (maioria das reações fisiológicas); aprendizagem de estímulo - resposta; aprendizagem de cadeias motoras e verbais; aprendizagem de discriminações e generalizações; aprendizagem de conceitos e aprendizagem de princípios.

A solução de problemas não é considerada um tipo de aprendizagem, mas sim a reorganização dos conceitos e princípios na estrutura cognitiva.

Em adição aos tipos de aprendizagem, Gagné (1971) propôs a divisão em domínios de aprendizagem que seriam os seguintes: 1. habilidades motoras; 2. informação verbal; 3. habilidades intelectuais; 4. estratégias cognitivas; e, 5. atitudes. É nessa direção que foram e são desenvolvidos nossos trabalhos, seguindo prioritariamente os princípios de ensino centrados no estudante, que apontam as direções relativas à psicologia que os professores deveriam seguir.

\section{Aprendizagem de conceitos e solução de problemas}

A solução de problemas é entendida como uma forma complexa de combinação dos mecanismos cognitivos disponibilizados a partir do momento em que o sujeito se depara com uma situação para a qual precisa buscar alternativas de solução.

Pode ser definida como um processo cognitivo que visa transformar uma dada situação em uma situação dirigida a um objetivo, quando um método óbvio de solução não está disponível para o solucionador. Apresenta quatro características básicas: é cognitiva, é um processo, é dirigida a um objetivo e é pessoal, pois depende do conhecimento prévio do indivíduo (BRITO, 2000). A solução de problemas é altamente dependente dos conceitos e princípios anteriormente aprendidos. Estes, disponibilizados na memória e combinados de forma a levar ao resultado final, permitem que a estrutura cognitiva se amplie e 
inclua os elementos novos, sejam os relativos ao conhecimento declarativo ou ao conhecimento de procedimentos (Figura 1).
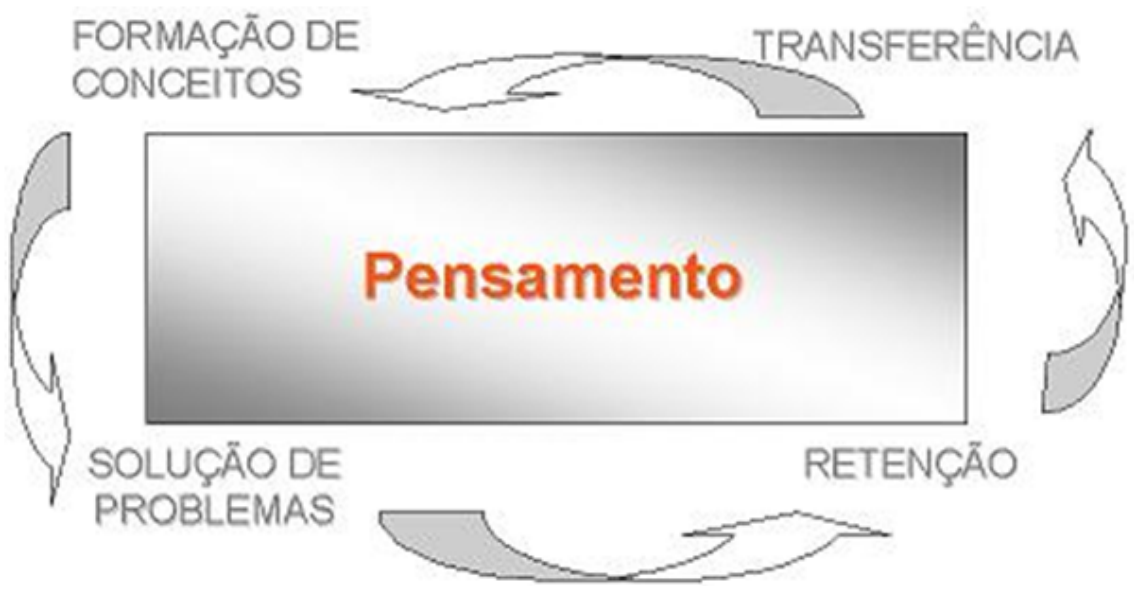

FIGURA 1 - O PENSAMENTO E A SOLUÇÃO DE PROBLEMAS

\section{Etapas da solução de problema}

A solução de problemas refere-se a uma atividade mental superior ou de alto nível e envolve o uso de conceitos e princípios necessários para atingir a solução. Pela estreita relação entre a solução de problemas (do ponto de vista da psicologia) e as exigências das disciplinas escolares, o entendimento sobre a solução de problemas teve um grande avanço; para isso contribuíram os estudos sobre inteligência, o desenvolvimento de testes psicológicos e toda a pesquisa desenvolvida ao longo do século passado.

Ao solucionar um problema matemático o indivíduo inicialmente percebe, tanto de maneira analítica como sintética, os elementos que o compõem. A percepção analítica é caracterizada pelo isolamento de diferentes elementos do problema, acesso diferenciado e estabelecimento de hierarquia entre eles. A percepção sintética ocorre à medida que o sujeito vai estabelecendo combinações e relações entre elementos componentes do problema.

Em um estudo onde os estudantes foram solicitados a descrever como haviam pensado para solucionar problemas, houve acentuada concordância de 
que a primeira etapa era a leitura cuidadosa do enunciado; em seguida, a tentativa de estabelecer elos entre a nova situação e outras semelhantes com as quais já tivesse se defrontado anteriormente, buscando, na memória de longo prazo, os elementos relacionados para, em seguida, testar a solução. Nas pesquisas sobre solução de problemas, realizadas pelo PSIEM, foi verificado que à medida que os estudantes avançam na escolaridade, mostram-se cada vez mais capazes de descrever as etapas pelas quais passa o pensamento, percebendo-os claramente.

Para que os estudantes construam formas eficazes de trabalhar com problemas e atinjam um domínio das tarefas inerentes às disciplinas, faz-se necessário que, desde o ingresso na escola, sejam levados a trabalhar com problemas desafiadores que os levem ao desenvolvimento de um pensamento flexível e produtivo na solução de problemas de diferentes tipos.

Ao trabalhar com a solução de problemas, o professor precisa estar atento às etapas pelas quais passa o estudante, isto é, com quais tarefas cognitivas ele se defronta:

1. Compreensão do texto;

2. Representação do problema;

3. Categorização do problema;

4. Estimativa de solução;

5. Planejamento da solução;

6. Autoavaliação do procedimento;

7. Autoavaliação do cálculo;

8. Redação da resposta, que leva o aluno a uma nova leitura da proposição do problema e compreensão do texto.

A solução de um problema se configura quando um indivíduo, frente a uma determinada situação, busca mecanismos significativos para atingir um resultado satisfatório, problematizando um ou mais aspectos, convertendo os elementos significativos disponíveis em dados do problema a ser solucionado, dirigindo o pensamento e o esforço mental na busca de mecanismos que permitam re-estabelecer o equilíbrio na estrutura cognitiva. É através da busca de possibilidades para se atingir um estado final desejado que se torna possível perceber os mecanismos de solução.

A pesquisa a respeito da solução de problemas matemáticos é importante porque a atividade de solução pode evidenciar diversas reações e processos cognitivos superiores, dentre os quais: a percepção, a representação, a imaginação e a formação de imagem mental, a retenção e a recuperação de informações 
contidas na memória. Krutetskii (1976), ao elaborar a representação de um problema, apontou que indivíduos matematicamente habilidosos são capazes de diferenciar claramente três elementos em um problema:

1. As relações que possuem significado matemático básico.

2. As quantidades não essenciais para aquele tipo de problema, mas que são essenciais naquela variante.

3. As quantidades supérfluas para aquele problema específico.

Assim, percebem o material matemático contido no enunciado verbal de um problema de forma analítica (isolando diferentes elementos da estrutura, acessando-os de maneira diferenciada, sistematizando-os e determinando sua hierarquia), e de forma sintética (combinando os elementos, estabelecendo, simultaneamente, relações matemáticas e funções de dependência entre eles). A representação de um problema matemático é constituída por vários determinantes, sendo a experiência anterior um dos principais.

Solicitado a solucionar um problema, o indivíduo forma uma representação do mesmo. Faz isso recuperando na memória os procedimentos adequados aplicáveis àquela situação. Esses procedimentos são espécies de "guias" e é exatamente essa representação que vai orientar a recordação sobre quais os procedimentos necessários para se atingir a solução. Assim, durante a solução de problemas alguns processos cognitivos superiores podem ser evidenciados, dentre eles a percepção, a representação, e a memória.

Para Sternberg (2000), a percepção consiste de um conjunto de processos psicológicos, pelos quais as pessoas reconhecem, organizam, sintetizam e fornecem significação, em nível cognitivo, às sensações recebidas dos estímulos ambientais, através dos órgãos dos sentidos. A percepção pode ser tratada de acordo com duas perspectivas: percepção construtiva e percepção direta. A percepção construtiva, ou inteligente, admite que o sujeito crie a percepção (a compreensão cognitiva) usando, a partir do estímulo, a informação sensorial, vista como fundamento da estrutura perceptual, além de utilizar outras fontes de informação. Nesta teoria, o pensamento de ordem superior é relevante na construção da percepção e, durante essa construção, várias hipóteses são testadas. Existe, portanto, uma interação entre a inteligência e os processos perceptivos; por isso também aquela percepção é chamada de percepção inteligente. $\mathrm{Na}$ teoria da percepção direta, as informações e o contexto são necessários e suficientes para a formação da percepção, e os indícios necessários à construção da percepção são estritamente inerentes ao estímulo (ver ALVES; BRITO, 2007).

A representação do conhecimento, segundo Sternberg (2000), é a forma pela qual o sujeito conhece objetos, eventos e ideias que são externos à sua 
estrutura cognitiva. A representação compreende várias formas do pensamento e permite criar e modificar as estruturas do conhecimento declarativo e de procedimento que o sujeito possui. Este processo cognitivo difere de acordo com a natureza do conhecimento, ou o conhecimento declarativo (corpo organizado de informações factuais), ou o conhecimento de procedimentos (algoritmos de execução de uma tarefa).

A representação do conhecimento declarativo é baseada no constructo de esquemas (estruturas mentais que representam o conhecimento, abrangendo uma série de conceitos inter-relacionados em uma organização significativa). As regras de produção, do tipo "se-então", são utilizadas para representar o conhecimento de procedimentos. A cláusula "se" da regra inclui um conjunto de condições que devem ser atendidas a fim de levar o sistema a executar a cláusula "então". A cláusula "então" corresponde a uma ação ou um conjunto de ações (STERNBERG, 2000).

Memória, segundo Baddeley (1999), é um sistema de armazenamento e recuperação da informação obtida através dos sentidos. Embora a palavra memória sugira a existência de um termo unitário, trata-se de um sistema múltiplo, pois não existe um único sistema, mas muitos; estes variam desde pequenos armazenamentos momentâneos, ao sistema de memória de longo prazo, que parece exceder extensamente em capacidade eflexibilidade ao maior ordenador disponivel. Trata-se de um mecanismo capaz de realizar a retenção de conhecimentos de qualquer tipo que, em algum momento, o sujeito possuiu. Além da capacidade aparentemente ilimitada, são suas características fundamentais a persistência duradoura de seus conteúdos e a pluralidade de códigos (devido à capacidade de retenção de conhecimentos de naturezas distintas, por diferentes meios para a aquisição), ainda que exista um predomínio de codificações semânticas.

\section{Afetividade: atitudes, crenças de autoeficácia em relação à mate- mática e autorregulação da aprendizagem}

O estudo das emoções voltou à literatura em psicologia educacional e, no Brasil, hoje, já existem muitos trabalhos relacionados a atitudes, crenças e concepções. Aliados a isso, há estudos sobre influências da família, do gênero, do tipo de escola dentre outros. Todo esse conjunto de variáveis influi na opção profissional, particularmente nas carreiras que envolvem a matemática.

Assim como as atitudes apresentam relação com a ansiedade, também 
outros aspectos da emoção estão presentes e diretamente associados ao comportamento ansioso em relação à escola. Vários pesquisadores, particularmente os ligados à área de psicologia da educação matemática, estão desenvolvendo estudos e programas de acompanhamento voltados à redução da ansiedade matemática e ao desenvolvimento de atitudes positivas em relação à matemática.

À medida que o indivíduo avança na escolaridade, ele vai desenvolvendo crenças, valores e atitudes em relação às diferentes disciplinas, e estas variam em intensidade. $\mathrm{O}$ desenvolvimento das atitudes está diretamente relacionado ao afeto, enquanto as crenças e valores estão mais relacionados ao componente cognitivo. Entretanto, não existe uma demarcação "palpável" entre os componentes afetivo, cognitivo e conativo, pois estes são interdependentes. O componente afetivo da atitude com relação à matemática inclui as emoções e os sentimentos, particularmente o afeto que o indivíduo sente frente a determinado fato, evento, objeto ou situação. É o gostar ou não de um determinado objeto (no caso, a matemática). O componente cognitivo refere-se ao conhecimento que o indivíduo tem a respeito do objeto. O componente cognitivo inclui também avaliações e apreciações feitas a respeito do objeto, sendo estas baseadas em argumentos racionais. $\mathrm{O}$ componente conativo refere-se à manifestação expressa do conhecimento e do afeto; o componente comportamental é o canal através do qual a atitude se expressa.

Ao apresentar atitudes negativas em relação à matemática, o estudante passa a apresentar comportamentos que vão desde um insucesso temporário até um grau extremo de aversão à disciplina. Os graus de afeto e emoção variam com a quantidade de experiências que os indivíduos desenvolvem ao longo dos anos escolares. O PSIEM acumulou ao longo de vinte anos mais de dez mil protocolos de estudantes dos diversos níveis de escolaridade com dados sobre essas dimensões. Foram desenvolvidas escalas diferenciadas de avaliação dessas dimensões em relação à estatística, geometria, frações, análise, álgebra, cálculo, por exemplo. Como afirmado anteriormente, esses trabalhos são analisados de forma qualitativa e quantitativa.

\section{A questão das habilidades}

Qualquer instituição escolar tem como uma de suas funções (a principal, em minha opinião) desenvolver plenamente o potencial dos estudantes a partir de suas habilidades, levando-os a adquirir as competências necessárias para atuar em um mundo em constante transformação. Isso, aliado à ideia de formar 
"bons pensadores", torna-se o objetivo central da educação.

O estudo das habilidades e da inteligência sempre ocupou um papel central na Psicologia e no grupo PSIEM, desde 1992, pela constatação da existência de diferenças nas maneiras de responder às exigências das tarefas matemáticas apresentadas e de processar a informação. Alguns trabalhos passaram a ter como problema central o estudo das habilidades matemáticas (com base na teoria de Krutetskii) e o papel desempenhado pela inteligência no processamento da informação (a partir dos estudos de Sternberg e Grigorenko).

Existe mais de uma maneira de definir o que é habilidade. Em primeiro lugar, habilidade é entendida como descrição, ou seja, o termo habilidade é usado para descrever ou fazer afirmações sobre o que a pessoa é capaz de fazer; por exemplo, dizemos que alguém possui habilidade musical ou "habilidade-paratocar-piano". Em segundo lugar, habilidade é entendida como explicação e, neste caso, as afirmações buscam explicar por que as pessoas fazem algo; por exemplo, o que uma pessoa possui que a torna hábil no tocar piano. A questão central das habilidades deve referir-se ao entendimento de como podemos executar certas atividades e não à descrição do que somos capazes de fazer.

O modelo mental das habilidades humanas refere-se não apenas à descrição daquilo que podemos executar, mas também a tudo aquilo que nos capacita a realizar determinadas tarefas com sucesso. Quando falamos de habilidade, estamos nos referindo sempre à descrição de uma atividade; por exemplo, fazer a modelagem de uma peça de vestuário. Mas também é importante a explicação do que é necessário para que o indivíduo consiga realizar essa atividade; por exemplo, destreza manual e conhecimento geométrico intuitivo são importantes para fazer a modelagem de uma peça de vestuário? Por quê?

Também é importante considerar os tipos de habilidades propostos por Sternberg (2000), que são: habilidade analítica, habilidade criativa e habilidade prática ("intuitiva"), além das variáveis do contexto. Todas as atividades apresentam um inter-relacionamento de habilidades e sub-habilidades, sendo que os componentes de uma habilidade só aparecem durante a execução de uma tarefa relacionada. Na caracterização dessas atividades relacionadas temos:

a) habilidade analítica: analisar teorias, criticar experimentos, avaliar conceitos.

b) habilidade criativa: gerar novas teorias, elaborar novos experimentos, imaginar como as teorias necessitariam ser modificadas se certos pressupostos mudassem.

c) habilidade prática: usar os conceitos, teorias e dados para conhecer e melhorar a vida cotidiana e o contexto de inserção.

Porém, o que geralmente ocorre é que a escola está mais interessada em desenvolver a habilidade analítica e o pensamento crítico, deixando os demais 
aspectos fora das atividades.

As habilidades são entendidas como estruturas mentais complexas que constituem uma síntese das propriedades e qualidades da mente; logo, incluem diversos aspectos desenvolvidos durante a execução adequada de uma atividade. Considerando que a função da escola é formar bons pensadores, é necessário que estas habilidades sejam desenvolvidas durante as aulas através de atividades planejadas, estruturadas e elaboradas em conjunto pelos professores, devendo perpassar todas as disciplinas. mática:

Para encerrar, eis alguns exemplos de componentes da habilidade mate-

- habilidade para pensar logicamente, na área das relações espaciais e quantitativas, dos números e símbolos alfabéticos e para pensar em símbolos matemáticos;

- $\quad$ habilidade para generalizar de forma abrangente e rápida os conteúdos matemáticos, as relações e as operações;

- habilidade para "resumir" os processos matemáticos e os sistemas correspondentes de operações, além da habilidade para pensar através de estruturas reduzidas.

Com relação às habilidades, os pesquisadores concordam que é necessário distinguir entre a habilidade escolar, comum para dominar a informação de uma área, reproduzi-la e usá-la independentemente (habilidade acadêmica), e a habilidade criativa, que permite a criação de um produto original que contém um valor social.

Os estudantes apresentam múltiplas habilidades, mas estas são pouco valorizadas nas avaliações das instituições educacionais porque os professores tendem a valorizar as habilidades analíticas (bem como a memorização) em detrimento das habilidades criativas e práticas.

Há necessidade de desenvolver procedimentos de avaliação dinâmica, uma vez que as abordagens estáticas para a avaliação da capacidade de aprendizagem ou do potencial de aprendizagem falharam ao prover os educadores do tipo de informação que eles necessitam para facilitar o desenvolvimento psicológico e $o$ avanço educacional dos estudantes.

Por conta dessa necessidade, estão sendo desenvolvidas atualmente no PSIEM/UNICAMP teses de doutorado que tratam das variáveis que influem no desempenho, comparando o modelo de avaliação estática e a avaliação dinâmica na área da matemática das avaliações em larga escala (SAEB, SARESP, Prova Brasil e Exame Nacional de Desempenho de Estudantes - ENADE). 


\section{REFERÊNCIAS}

ALVES, E. V.; BRITO, M. R. F. Relações entre a percepção da estrutura de um problema, a memória e a memória matemática. Temas em Psicologia, v. 15, n. 2, p. 207-215, 2007.

AUSUBEL, D.; NOVACK, J. D.; HANESIAN, H. Educational psychology. A cognitive view. 2. ed. New York: Holt, Rinehart \& Wiston, 1978.

BADDELEY, A. D. Essentials of human memory. Hove/UK: Psychology Press, 1999.

BRITO, M. R. F. de. "Este problema é difícil porque não é de escola": a compreensão de problemas aritméticos verbais por crianças da escola fundamental. Temas de Psicologia, v. 8, n. 1, p. 93-109, 2000.

. Contribuições da psicologia educacional à educação matemática. In:

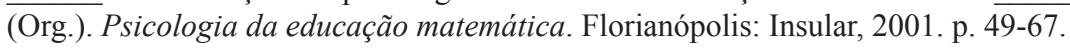

GAGNÉ, R. Como se realiza a aprendizagem. Tradução de: TOVAR, T. M. R. Rio de Janeiro: Livros Técnicos e Científicos, 1971.

KRUTETSKII, V. A. The psychology of mathematics abilities in schoolchildren. Chicago: The University of Chicago Press, 1976.

QUINTILIANO, L. C. Estratégias de solução, conhecimento declarativo e de procedimentos na solução de problemas algébricos. Dissertação (Mestrado em Educação) - Grupo de Pesquisa em Psicologia da Educação Matemática, Faculdade de Educação/UNICAMP, Campinas, 2005.

STERnBerG, R. J. Psicologia cognitiva. Tradução de: OSÓRIO, M. R. B. Porto Alegre: Artes Médicas, 2000.

UTSUMI, M. Atitudes e habilidades envolvidas na solução de problemas algébricos. Um estudo sobre a estabilidade das atitudes e as habilidades matemáticas de estudantes das séries finais do primeiro grau. Tese (Doutorado em Educação) - Grupo de Pesquisa em Psicologia da Educação Matemática, Faculdade de Educação/UNICAMP, Campinas, 2000. 
